\title{
El empoderamiento de los indios
}

\author{
Jorge Silva Riquer
}

Thomas Calvo, 2010

Vencer la derrota. Vivir en la sierra zapoteca

de México (1674-1707)

El Colegio de Michoacán, Centro de Estudios Mexicanos

y Centroamericanos, Centro de Investigaciones y Estudios

Superiores en Antropología Social, Universidad Autónoma

Benito Juárez de Oaxaca, México, 298 pp.

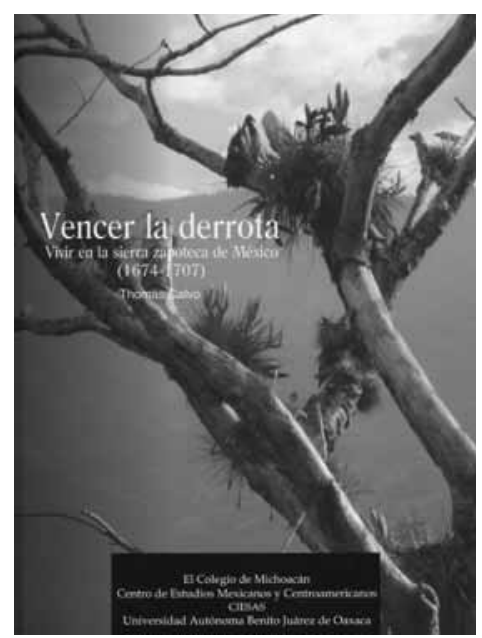

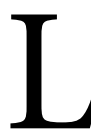

a historia depara retos, problemas y preguntas, todos nuevos, de manera permanente, constante, referidos a la vida y a las contradicciones que se asumen con el cotidiano en el que se expresan los intereses particulares, de grupo, de género, de formas múltiples que nos provocan a realizar la aventura de reconstruirlos, de interpretarlos, de analizarlos para dar una explicación posible. El reto es enorme, las condiciones son

\section{The Empowerment of Indians}

Jorge Silva Riquer: Universidad Michoacana de San Nicolás de Hidalgo, Morelia, Michoacán, México jsriquer@gmail.com

Desacatos, núm. 41, enero-abril 2013, pp. 204-207 propicias y el lance se inicia en cada investigación. El texto que nos presenta Thomas Calvo se inserta en esa perspectiva de análisis, se enfrenta abiertamente, contiende y propone interpretaciones apropiadas a las características del historiador y de su tiempo, una vieja discusión que sigue vigente, y seguirá, nos indica en su "Prólogo" y a lo largo del trabajo. A partir de una inquietud histórica, se acerca a un asunto ocurrido a fines del siglo XVII y principios del XVIII para intentar ubicar un cambio de condiciones señalado por varios historiadores y que Calvo ha hecho suyo. La inquietud de buscar dicho cambio lo lleva a aproximarse a la realidad indígena de Villa Alta, Oaxaca, donde las condiciones, las formas de 
apropiación y el empoderamiento de la realidad colonial española asumieron características particulares, según reseñan él mismo y los trabajos de otros especialistas sobre esas condiciones. De este modo, abre la posibilidad de conocer e interpretar las formas que asumieron los grupos de indios en condiciones particulares, bajo la mirada y la incidencia del historiador del presente.

El reto que Calvo asume es interesante. Intenta sobre todo hacer una interpretación más equilibrada para entender los avatares de los grupos y de los personajes que se enfrentaron en momentos importantes para controlar, asumir y disponer de las decisiones sobre la comunidad y sus beneficios. Estas prácticas, por sí mismas, señalan y reiteran la necesidad de no uniformar las condiciones de una realidad a partir de una serie de evidencias, pues las generalizaciones han bloqueado de alguna manera las interpretaciones históricas y han impedido un análisis más completo y complejo a las condiciones sociales que se quiere explicar. Un asunto señalado desde tiempo atrás por los historiadores, pero que aún prevalece, es que se reprobaba constantemente a la historia económica de olvidar a los seres humanos y sus formas de empoderamiento. Es necesario identificar este aspecto para evitar las interpretaciones sin explicación y para no perder de vista las complejidades de una sociedad. La llamada de atención no se queda sólo en lo anterior, también nos reitera la utilidad de los archivos judiciales, que guardan información sustantiva para recrear esas realidades. Ya los estudios clásicos habían mostrado la importancia de ésos y otros repositorios por las posibilidades de reproducción de espacios, condiciones y realidades históricas, pero sobre todo de reinterpretación. Recordemos los trabajos de Huizinga y de Le Roy Ladurie, entre otros, que a partir de ubicar las condiciones recrean el contexto que da paso a las representaciones sociales de grupos que controlan el poder, figuras antagónicas que asumen distintas formas de control, en fin, ver a los seres en sus propias condiciones sociales. En este sentido, el texto de Calvo es un ejemplo acabado de esas interpretaciones.

Como señala en la "Introducción", su análisis es un intento de no alterar las condiciones sobre las que se realizaron los actos. El lugar es la alcaldía de Villa Alta, en el pueblo de Yasona, en Oaxaca. Las evidencias se refieren a la apropiación y empoderamiento de las condiciones españolas e indígenas y a la permanencia de ambas en una realidad colonial. Los personajes son caciques, macehuales y otros que asumieron y aprendieron las condiciones impuestas por los españoles, las mantuvieron como formas propias en una comunidad alejada y no de las autoridades españolas donde los intereses $\mathrm{y}$ creencias se recrearon a partir de sus propias interpretaciones. Bajo las contradicciones propias de los actores y sus prácticas, el autor desarrolla un análisis complejo y sugerente a partir de las evidencias, en donde los actores establecen relaciones de poder ubicadas en las necesidades de control sobre el espacio, la sociedad y la cosmovisión. El juego que entablan los actores, de manera individual o en grupo, según las condiciones prevalecientes, es una manera amplia de entender y ejercer un poder que se asume en dos condiciones características de la sociedad indígena de ese periodo que fluctúan entre el ejercicio de la sociedad india y de la colonial, bajo los principios de la organización sincrética que estaban construyendo. El aprendizaje, la utilización y la recreación de las formas de poder es una constante en Yasona, y sus actores no se aferran a una forma en particular, sino que adoptan y combinan perfectamente las prácticas políticas vigentes de su pueblo.

Las formas sincréticas de poder quedan evidenciadas en la manipulación y el control que ejercieron ciertos personajes desde su posición, por ser herederos del cacicazgo indígena 
o porque lo asumieron como propio - esa definición que se ha utilizado para entender la movilidad social asumida en los pueblos de indios, en cualquier lugar y condición-, así como en las relaciones establecidas a partir de ellas para controlar y manipular a su vez las decisiones a favor de un grupo o personaje, una constante en las relaciones humanas. La explicación que nos ofrece Calvo de cara a esas relaciones y condiciones no se queda sólo en la parte política, sino que se extiende a otras esferas relacionadas: por ejemplo, las prácticas religiosas, el sincretismo y el paganismo serán una constante en estos pueblos, como formas propias y de
La explicación de los hechos nos lleva a entender cómo empiezan a organizarse y sobre todo cómo controlan las formas y prácticas que permiten un rejuego importante a ciertos personajes, ya sea que se ubiquen en un bando o en otro, según las condiciones que enfrentan, pero también la habilidad y el sentido de retraerse de la esfera pública para actuar desde lo privado o desaparecer para no perder el control o retomarlo. Las habilidades política y religiosa fueron utilizadas y practicadas para permitir a esos actores tener el poder y ejercerlo en su provecho. Como señala el autor, dicho poder no radicaba en el dinero, sino en la concepción, en lo político, en lo imaginario, algo más complejo y de mayor impacto, evidentemente sin menoscabo del primero.

Con gran sensibilidad y cuidado, Calvo reconstruye, con base en hechos al parecer aislados, un evento que por su magnitud cambia la explicación de una realidad india en el pueblo de Yasona. A partir de un pleito de alcohol y muerte, clásico en esas condiciones, se teje una serie de relaciones políticas y religiosas que dan como resultado un rejuego de poderes para controlar el espacio/pueblo y establecer las relaciones que permiten mantener las prácticas sincréticas asumidas por los indios en el periodo colonial. Una realidad compleja y llena de simbolismos que permitía ascender en la escala social y política a grupos y personajes. La consolidación de estos mecanismos llegó a abarcar un espectro amplio, que va desde la construcción de casas sólidas - la mayoría de las casas de Yasona eran de paja y maderahasta la distribución de los cargos que debían asumirse por ejercer las funciones del pueblo y demás responsabilidades que pudieran retribuir prestigio, siempre y cuando no violentaran las relaciones internas. Todo con el reconocimiento de la autoridad real y con el apoyo de los habitantes del pueblo a través de la identificación con el cacicazgo original. Tal es el caso de los protagonistas que se analizan en el texto. Las habilidades política y religiosa son evidentes en cada personaje y sus grupos de poder, mismos que sostienen una lucha constante, abierta y cerrada, dependiendo de las condiciones y los tiempos en los que se enfrentaron. La organización del texto de Calvo facilita su lectura y la comprensión de los procesos de consolidación de los tres personajes, de sus grupos de poder y de sus prácticas políticas $\mathrm{y}$ religiosas como formas propias $\mathrm{y}$ aceptadas por los pobladores de Yasona. Destaca la relativa lejanía del pueblo con la alcaldía mayor de Villa Alta. Su relación con los poderes terrenales y espirituales hace posible a sus habitantes asumir sus propias formas $y$ prácticas, las cuales les dan reconocimiento y poder para enfrentarse por el control, siempre con el respaldo de las autoridades reales. El autor documenta varios casos en que la presencia de la autoridad civil se hace evidente a partir de medidas que alteran los planes de los grupos indígenas, pero sin ser causa de enfrentamientos abiertos, más bien ocultos, soterrados, lo que les permite no perder lo obtenido, sino mantenerlo y continuar con sus prácticas.

Lo mismo sucede con las prácticas religiosas: a pesar de asumir la fe católica como elemento necesario para su conversión y participación de la organización colonial, los indios mantienen y recrean los ritos 
religiosos prehispánicos, que convierten a estos personajes en los sacerdotes, indispensables para poder llevarlos a cabo, pues sin ellos no se podrían recrear. Esto constata el control ejercido por esos personajes y la habilidad para profesar las formas impuestas por las autoridades españolas, civiles y religiosas, y enfrentar a otros grupos en el juego político establecido al interior de Yasona. La recreación de las prácticas religiosas y políticas de los habitantes era una constante. Los ritos religiosos se celebraban de acuerdo con un patrón que se aprendía y se cultivaba de forma constante, en los cerros del pueblo se guardaban los ídolos y se encontraban los vínculos de los mundos. Los señores de Yasona enseñaban y daban la iniciación a los practicantes y futuros propagadores de tales ritos. La recreación se centraba en ídolos, pinturas y ritos, a pesar de ejercer el rito católico, que estaba casi ausente de Yasona por lo alejado de Villa Alta y por la falta de un cura que atendiera las necesidades espirituales de los indios.

El sincretismo religioso y político era más que eso: una actividad constante y sin contraposición con las disposiciones coloniales, por lo que el poder de los tres personajes fluctuó entre ambos mundos y les permitió, por lo menos hasta el siglo xviII, ejercer esas prácticas en su beneficio y en el del pueblo en general.
Al parecer, los demás pueblos dentro de la alcaldía de Villa Alta estaban en las mismas condiciones. Cajonos, Yalalag, Tabaa y Betaza son ejemplos claros de esos procesos, de las prácticas llevadas a cabo por los caciques de cada pueblo. Los resultados fueron distintos en cada caso. Calvo lo explica de manera comparativa y analítica, lo que da un significado mayor al caso de Yasona en torno a las respuestas de los indios ante las medidas aplicadas por los españoles respecto de las relaciones políticas, administrativas y religiosas. La vitalidad de estas prácticas bajo los parámetros religiosos sincréticos asimilados de los indios es una constante en ese espacio y en ese tiempo. Por último, en relación con Yasona en Villa Alta, Oaxaca, Calvo hace una reflexión y compara varios factores importantes que determinaron cambios y nuevas formas de uso y práctica colonial en torno a las condiciones económicas y de salud sufridas por la población indígena. Entre epidemias y crisis agrícolas, las condiciones fueron un agravante a las prácticas cotidianas de la población. Sus respuestas fueron asumidas de acuerdo con las necesidades de explicación. Ante la ausencia de ministros civiles y religiosos, los indios buscaron respuestas y las hallaron en las prácticas sincréticas religiosas, pero también por medio de la asunción del poder: los grupos fueron más agresivos, más hábiles. La aculturación asumida por algunos de ellos se convirtió en un arma para tomar el control de los pueblos, de sus representaciones, y sus respuestas eran entonces acordes con las realidades y las explicaciones que encontraron.

Thomas Calvo hace una reflexión acabada sobre una realidad particular en una comunidad indígena, escasa en población y en riqueza, pero con una participación y ejercicio del poder amplios y complejos. La búsqueda de respuestas ante las condiciones se hace evidente en este texto, donde predominan la habilidad, el conocimiento y la explicación profunda de los hechos. La lectura de este libro se convertirá en un referente historiográfico indispensable para entender el proceso de transición entre los siglos XVII y xviII, pues la observación de Calvo es clara y contundente. No empecemos a generalizar a partir de las evidencias y explicaciones que ofrece este trabajo, porque perderemos de vista su complejidad. Se trata de un trabajo de calidad, propositivo, analítico, esas condiciones que los grandes maestros han discutido y ejercido y que hemos olvidado y dejado de cultivar. Habrá que seguir el ejemplo de Vencer la derrota. Vivir en la sierra zapoteca de México (1674-1707) de Thomas Calvo para recuperar esa tradición. 